\title{
RECUPERAÇÃO DE HASTE DE SONDAGEM POR MEIO DE PROCESSO DE SOLDAGEM*
}

\author{
Marcus Vinícius da Silva Jardim ${ }^{1}$ \\ Marciano Quites Macedo² \\ Fernando Gabriel da Silva Araújo ${ }^{3}$
}

\section{Resumo}

Neste trabalho foi estudada a recuperação de hastes de sondagem por meio do processo de soldagem por fricção, assim como as propriedades mecânicas obtidas neste processo. As amostras foram retiradas em tubos de aço SAE4130 trefilados sem costura no diâmetro externo de $88,9 \mathrm{~mm}, 5,5 \mathrm{~mm}$ de espessura de parede e com $300 \mathrm{~mm}$ de comprimento total. Foram realizados ensaios metalográficos e mecânicos nas amostras do tubo com o objetivo de verificar e comparar as características do tubo em estado de entrega com os resultados obtidos na junta soldada. A junta soldada por fricção apresentou uma microestrutura constituída de bainita inferior e martensita na região da solda. Na Zona Termomecanicamente Afetada - ZTMA observou-se a presença de Bainita, ferrita e perlita. Em consequência das microestruturas obtidas, o valor de dureza na solda por fricção foi maior em relação à ZTA e ao metal base, o que resultou em rompimento na região do metal base durante o ensaio de tração. $O$ método de soldagem por ficção mostrou-se eficaz para a recuperação de hastes de sondagem.

Palavras-chave: Sondagem; Haste; Perfuração; Soldagem; Fricção.

\section{RECOVERY OF DRILLING ROD THROUGH WELDING PROCESS}

\begin{abstract}
In this paper was studied the recovery of drilling rod through friction welding process as well as the mechanical properties obtained. The samples were extracted from SAE 4130 steel seamless pipe with outside diameter of $88.9 \mathrm{~mm}, 5.5 \mathrm{~mm}$ thickness and $300 \mathrm{~mm}$ in total length. Metallographic and mechanical tests were carried out on a sample with the purpose of verifying and comparing characteristics of the pipe on delivered state with results obtained at the welded joint. Friction welded joint showed a microstructure composed of lower bainite and martensite. Bainite, ferrite and perlite was observed on the thermomechanically affected regions. In consequence of the microstructures obtained, the hardness value in the friction weld was high in relation to the HAZ and the base metal, which resulted in a rupture of the latter region during tensile testing. Friction welding method proved to be effective for drilling rod recovery.
\end{abstract}

Keywords: Drilling; Drilling rod; Welding; Friccion.

1 Mestrando Eng. de Materiais, REDEMAT/UFOP, Universidade Federal de Ouro Preto, Eng. Metalurgista.

2 Geosol, M.Sc/REDEMAT/UFOP.

3 Ph.D., Physics Department/REDEMAT/UFOP. 


\section{INTRODUÇÃO}

Um dos métodos mais utilizados para os estudos geológicos é a pesquisa mineral. Os dados obtidos são de importância para o planejamento de lavra, beneficiamento de commodity e também para a determinação do tamanho da reserva mineral. Por meio do método de sondagem rotativa diamantada, conhecido como wireline ${ }^{[1]}$, são retiradas amostras do mineral a ser explorado desde a superfície até grandes profundidades, os quais, retratam fielmente as características físicas, químicas e geológicas da rocha atravessada. [2]

Dentro do processo de sondagem, as hastes de perfuração são responsáveis por transferir o torque aplicado pela sonda até a coroa de perfuração, que é a ferramenta de corte. Desta forma a quantidade de haste utilizada em um furo de sondagem é determinada pela profundidade do furo e pelo desgaste provocado durante a execução do mesmo. As hastes duram em média $50 \mathrm{~m}$ de perfuração, o que resulta em um consumo relativamente alto quando comparado com as demais ferramentas tubulares da composição wireline. O valor de uma haste importada chega a ser de três a quatro vezes maior em relação ao de uma haste de fabricação nacional. Estes valores são muito representativos para uma empresa de perfuração. Devido a este fator, a empresa busca investir em hastes de melhor qualidade e por um processo de recuperação cada vez mais eficiente. Além disso, o custo do tubo trefilado sem costura, também é elevado.

Eventualmente, nas hastes, somente as roscas são mais danificadas, devido às inúmeras conexões e desconexões realizadas durante uma sondagem. Sendo assim, atualmente dois processos são utilizados para a recuperação de hastes wireline, sendo eles:

- Corte das roscas usadas e solda de novas ponteiras pelo processo de arco elétrico com gás de proteção para posterior tratamento térmico e usinagem.

- Corte das roscas usadas, usinagem de novas roscas no tubo e conexão de ponteiras tratadas e rosqueadas previamente com a utilização de adesivo para alto torque.

No processo de recuperação por soldagem a arco elétrico, como no processo MIG/MAG, muitas vezes podem ocorrer fissuração por hidrogênio e trincas por fragilização da zona termicamente afetada (ZTA), devido a formação de martensita. Afim de evitar este tipo de falha, principalmente em ligas com médio e alto teor de carbono com outros elementos de liga, tais como SAE4130, 1045 e 1541, que são as mais utilizadas para a fabricação de hastes de perfuração, geralmente se aplica o pré-aquecimento e o pós-aquecimento, além da escolha correta do metal de adição [3]. Estas etapas de aquecimento antes e após a soldagem, acarretam em um aumento no tempo de produção, o que torna o processo MIG pouco viável.

Já no processo de usinagem de roscas para a conexão de uma nova ponteira nas hastes, tem-se 4 etapas de usinagem a mais no processo, o que encarece o método e o torna mais lento. Além deste fator, alguns operadores relatam que no momento da desconexão das hastes, se não posicionar os equipamentos que fazem a desconexão, exatamente na rosca entre as hastes, pode ocorrer a desconexão entre a ponteira e o tubo. Outro fator se deve ao fato de que mesmo com o adesivo para

\footnotetext{
${ }^{1}$ Método wireline é composto de um tubo externo completado na sua extremidade inferior por um calibrador ou luva e por uma coroa de perfuração. Na parte interna encontra-se um tubo retrátil com um anel de retenção do testemunho na extremidade inferior e na parte superior uma cabeça giratória com rolamentos e um sistema de travas e de lançadeira com pegador do tubo interno denominado over shot [1].
} 
alto torque, o equipamento de sondagem possui capacidade de torque superior ao da resistência proporcionada pelo adesivo.

O uso de técnicas de soldagem por fricção para a união de tubos pode render reduções significativas de tempo de processamento e de mão de obra necessária, garantindo repetibilidade na soldagem quando comparado a processos convencionais de fusão. Trata-se de um processo de soldagem no estado sólido, cujo calor necessário para a união de partes metálicas similares ou dissimilares, é causado pelo atrito entre os materiais em movimento relativo, e a deformação final pela aplicação de uma forma de compressão logo após o término do movimento entre as peças $[4,5]$.

Existem dois tipos de soldagem por fricção, o processo russo (impulsão direta) e o processo americano (impulsão inercial), sendo a principal diferença entre eles a característica de rotação [5]. No processo de impulsão direta, por meio de um pistão hidráulico, uma peça é fixa e é deslocada linearmente até a outra peça que possui movimento giratório com velocidade pré-determinada e constante, garantido por meio de um motor elétrico. No processo de impulsão inercial, um dos materiais é fixo e o outro é conectado a um volante, que ao adquirir uma velocidade angular prédeterminada, armazena a energia adquirida.

O método aplicado para a soldagem por fricção, inercial ou direto, também influencia na resistência à fadiga, isso porque a força aplicada durante as etapas de fricção e forjamento alteram a quantidade de material plastificado presente na junta soldada. Assim, a união de materiais a baixa velocidade de rotação, cujo material plastificado foi removido da junta, apresentam uma maior resistência à fadiga se comparado ao material onde a rebarba não foi retirada, representando um aumento de cerca de $20 \%$. De modo geral, as juntas soldadas, atingem facilmente $80 \%$ da resistência do material de base [6].

Outro fator que afeta significativamente a resistência à fadiga é a dureza das juntas soldadas. Normalmente, as fissuras são originadas em áreas amolecidas do material soldado. Um elevado teor de carbono na junta soldada, normalmente, gera uma falha no material de base, de modo que a geometria da rebarba se torna menos importante, uma vez que o efeito da dureza nas diferentes regiões da solda é mais significativo que o efeito de concentrador de tensões causado pela rebarba do material plastificado. No caso de aços com baixo teor de carbono, o efeito da concentração de tensões é responsável pela maior parte das falhas por fadiga. [6]

De acordo com [7], um fator de extrema importância na soldagem por fricção de tubos é a análise de inclusões nos materiais a serem unidos, sendo que ocorre uma reorientação das inclusões durante a soldagem, reduzindo as propriedades de resistência a tração e tenacidade.

As formas de recuperação hoje aplicadas, resultam em uma redução de custo considerável por metro de rocha perfurada, porém não são métodos eficazes. Há problemas metalúrgicos relacionados ao método de soldagem atual ou ainda, devido a problemas operacionais com método que utiliza o adesivo para alto torque. Desta forma surge a necessidade de estudar um novo método de recuperação que elimine os problemas descritos. Desta forma, foi estudado neste trabalho o método de soldagem por fricção como meio de buscar reduzir o tempo de produção na recuperação das hastes de sondagem.

\section{MATERIAIS E MÉTODOS}


Tubos de fabricação nacional, trefilado e sem costura, de grau SAE4130 com diâmetro externo de $88,9 \mathrm{~mm}$ e diâmetro interno de $77,8 \mathrm{~mm}$ foram utilizados neste estudo. Trata-se de um aço baixa liga comumente aplicado em máquinas e ferramentas devido suas propriedades mecânicas. A composição química deste aço é mostrada na Tabela 1.

Os testes de soldagem por friç̧ão foram realizados nas dependências da MTI Welding Technologies. A solda foi realizada pelo processo inercial, utilizando o equipamento de modelo 40ton Direct Drive, mostrado na Figura 1. Os parâmetros utilizados foram: rotação de 1726RPM e força de atrito de 684Psi.

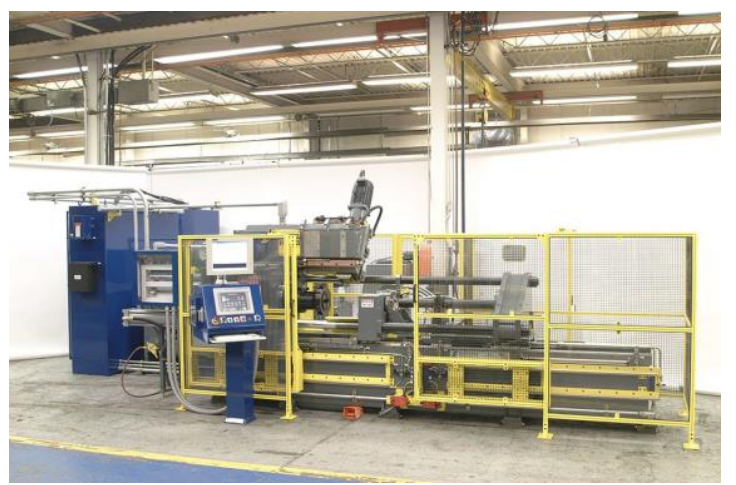

Figura 1. Equipamento de solda por Fricção.

Fonte: Autoria própria

Como forma de se investigar as propriedades de tubos comerciais desenvolvidos para a atividade de perfuração em sondagem geológica, foram realizados ensaios metalográficos, utilizando microscopia óptica e ensaio de tração nos tubos no estado de entrega e soldados por Fricção. Na avaliação da microestrutura, as amostras foram embutidas em resina e em seguida desbastadas em um plano com as lixas de grão 180, 220, 320, 400, 600, 800, 1000 e 1200 mesh. Posteriormente, a amostra foi polida com pasta de diamante de 6,3 e $1 \mu \mathrm{m}$. Para revelar a microestrutura a amostra foi atacada com nital de concentração $2 \%$ durante alguns segundos. Os corpos de prova para o ensaio de tração foram confeccionados em um equipamento de usinagem automatizado conforme a norma ASTM A370.

As juntas soldadas por fricção foram submetidas ao ensaio de microdureza Vickers de acordo à norma ASTM E384. Foi utilizado o Microdurômetro Shimadzu HMV2000 com uma carga de $0,025 \mathrm{~kg}$ aplicados em $10 \mathrm{~s}$, sendo: três pontos no metal base (MB); três pontos na zona afetada pelo calor (ZTA); três pontos na zona de mistura (ZM). O objetivo é traçar o perfil de dureza longitudinal na junta soldada para avaliação da junta soldada.

\section{RESULTADOS E DISCUSSÃO}

A Tabela 1 apresenta a composição química do aço SAE4130 estudado. Essa composição química está em conformidade com o especificado pelo fabricante Vallourec Brasil S.A. A partir do valor percentual em peso da liga, destaca-se o carbono equivalente (CE), igual a $0.60 \%$, calculado através da equação 1[8] desenvolvida pelo International Institute of Welding (IIW). O CE é um índice do grau de soldabilidade do aço e quando seu valor é superior a 0,45\%, é um indicador da sensibilidade à fissuração a frio para aços temperáveis. Também indica a necessidade de um pré-aquecimento antes da soldagem. 
carbono é o elemento mais significativo, sendo o responsável pela dureza da microestrutura martensítica e em menor grau, também pela dureza na microestrutura bainítica [9]. Segundo [10], a incorporação de elementos de liga contribui para reduzir tanto a temperatura de pré-aquecimento necessária ao se efetuar a união dos metais, como a redução na incidência de trincamento no cordão de solda.

Tabela 1. Composição Química do aço SAE4130 utilizado (\%peso).

\begin{tabular}{|c|c|c|c|c|c|c|c|c|c|}
\hline Elemento & $C$ & $M n$ & $P$ & $S$ & Si & $\mathrm{Ni}$ & $\mathrm{Cr}$ & $\mathrm{Cu}$ & Mo \\
\hline & 0,280 & 0,530 & 0,007 & 0,001 & 0,230 & 0,020 & 0,920 & 0,010 & 0,220 \\
\hline & $A I$ & $V$ & $N b$ & $T i$ & & CE & & & \\
\hline & 0,034 & 0,008 & 0,000 & 0,001 & & 0,60 & & & \\
\hline
\end{tabular}

A Figura 2 mostra a microestrutura do aço SAE 4130. A microestrutura é constituída de perlita (Fig.2a - grãos escuros; Fig.2b - grãos claros) e ferrita pró-eutetóide (Fig.2a - grãos claros; Fig.2b - grãos escuros), apresentando estrutura bandeada, comum aos processos de laminação e trefilação do tubo e uma fração volumétrica de ferrrita de $\boldsymbol{V}_{\alpha}=(\mathbf{4 8} \pm \mathbf{0 , 6}) \%$. A microestrutura apresentada pela amostra no estado de entrega é uma microestrutura típica de um aço microligado. O Gráfico 1 apresenta o perfil de microdureza Vickers realizado ao longo da espessura do tubo.

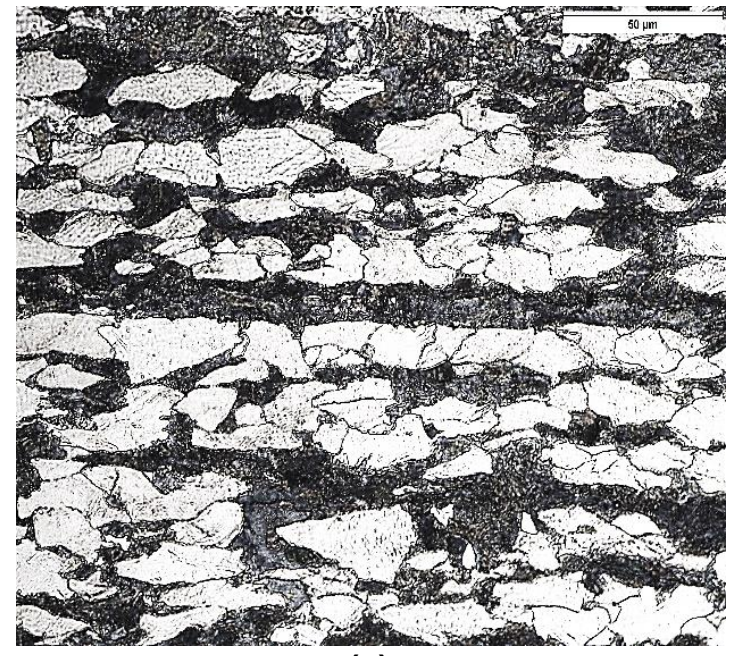

(a)

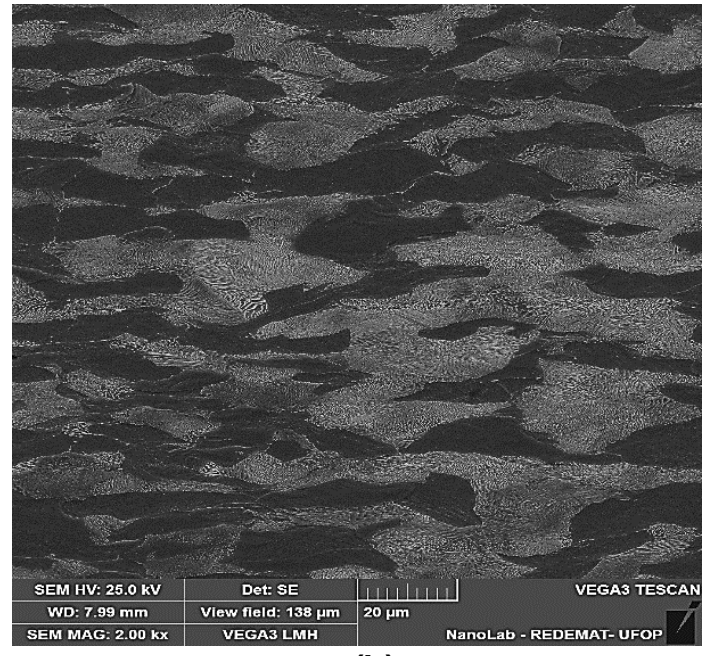

(b)

Figura 2. Ferrita+Perlita em estrutura bandeada do tubo SAE 4130 no estado de entrega. Em (a) imagem MO, 500X e (b) imagem em MEV, 2000X. Ataque Nital 2\%.

Fonte: Autoria própria. 


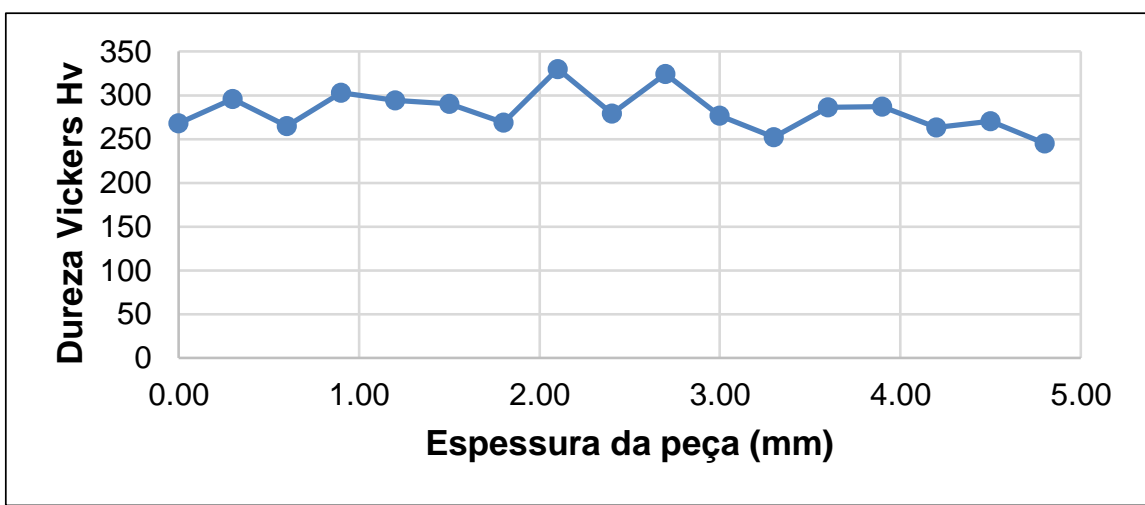

Gráfico 1. Perfil de microdureza Vickers ao longo da espessura do tubo no estado de entrega.

Fonte: Autoria própria.

A Tabela 2 apresenta as principais propriedades obtidas no teste de tração para o aço SAE4130 no seu estado de entrega. O material, apresentou um comportamento dúctil com um limite de resistência médio de 889Mpa e um limite de escoamento médio de 760,6Mpa.

Tabela 2. Propriedades mecânicas média do tubo SAE4130 no estado de entrega.

\begin{tabular}{c|c|c|c}
\hline Aço/Propriedades & LR (Mpa) & LE (Mpa) & Al (\%) \\
\hline SAE4130 & 889 & 760,6 & 15 \\
\hline \multicolumn{4}{c}{ Legenda: LR-Limite de resistência; LE-Limite de escoamento; Al-Alongamento. }
\end{tabular}

A Figura 3 apresenta a curva de teste de tração convencional com os valores médios obtidos a partir de três corpos de prova.

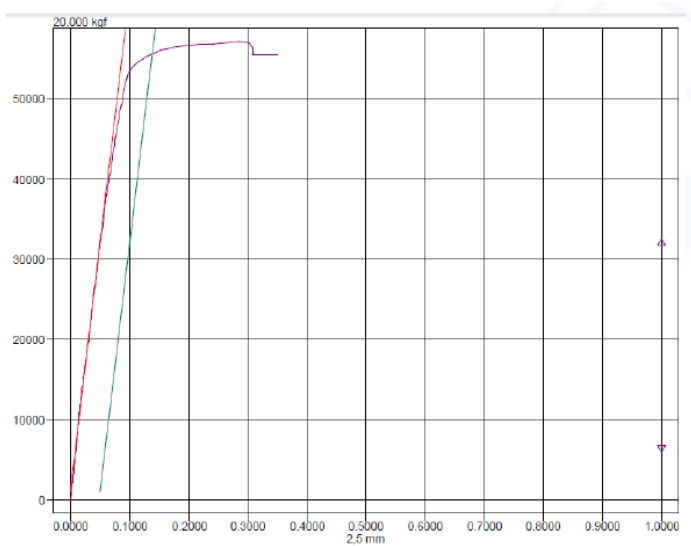

Figura 3. Curva do teste de tração do aço estudado no estado de entrega.

Fonte: Autoria própria.

A Figura 4 mostra a macrografia da junta soldada por fricção onde é possível verificar as dimensões da zona termomecanicamente afetada pelo calor e da zona de mistura. A junta soldada apresentou uma ZTMA com largura média de 0,643mm enquanto uma zona de mistura alcançou um mínimo de $0,377 \mathrm{~mm}$ no centro da peça. O tamanho e forma destas regiões deixam claro que os parâmetros de energia, força axial e a velocidade de rotação, alcançaram nível médio de acordo com [11].

A Figura 5 mostra a região da ZTMA, caracterizada por apresentar menor grau de deformação plástica, contudo, suficiente para promover a recristalização e/ou recuperação do material. É observada uma microestrutura ainda bandeada, porém com deformação no sentido de rotação da solda por fricção, constituída de ferrita (grãos claros) e de agregados de ferrita+carbonetos (grãos escuros). 
A Figura 6 mostra a região de mistura da solda na qual é possível verificar a presença de bainita inferior, uma mistura não lamelar de ferrita e cementita numa escala extremamente fina, que se forma a uma temperatura de aproximadamente $300^{\circ} \mathrm{C}[12]$.

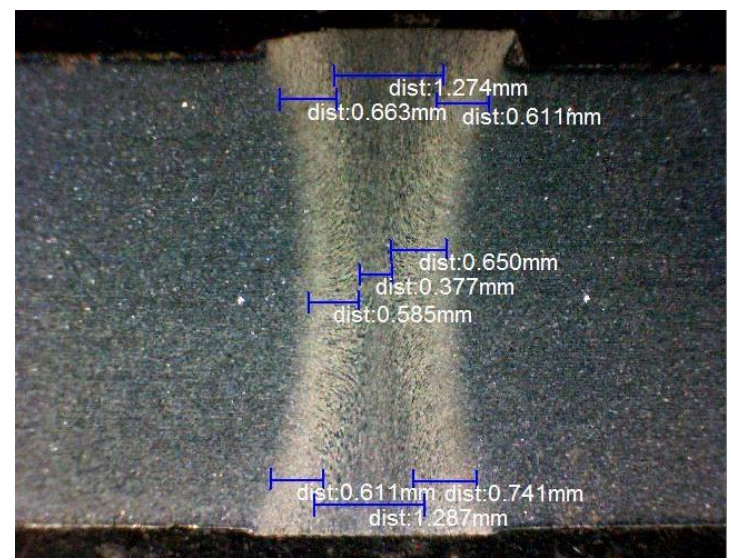

Figura 4: Macrografia da junta soldada por fricção.

Fonte: Autoria própria.

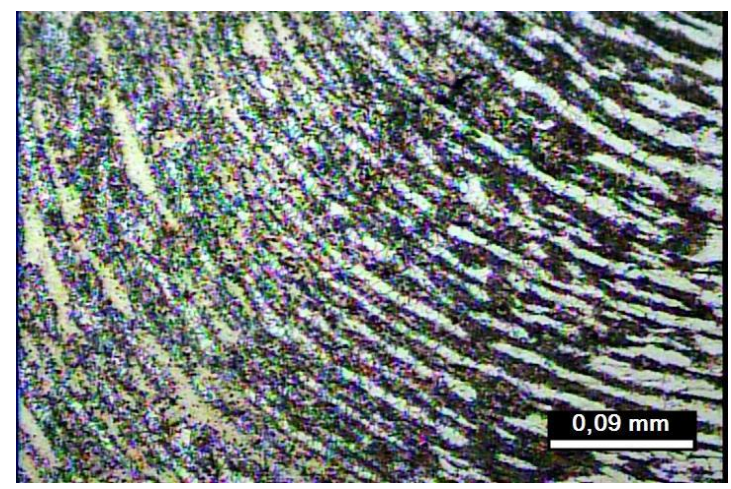

Figura 5: Micrografia da ZTMA com presença de ferrita e agregado ferrita+carboneto com deformação no sentido de rotação.

Fonte: Autoria própria.

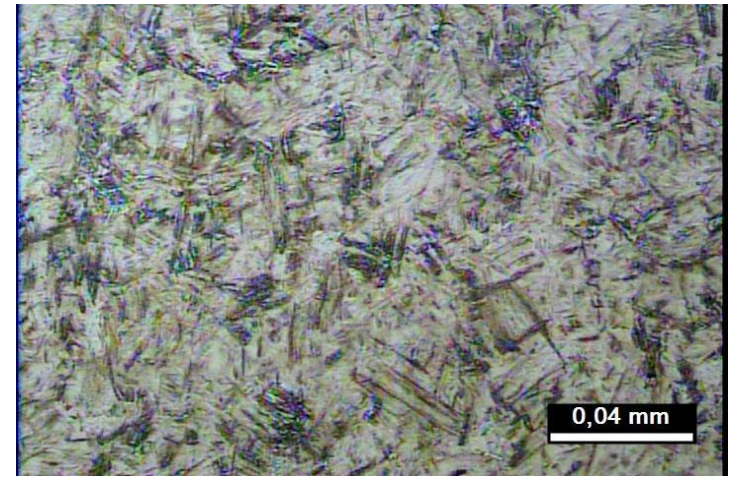

Figura 6: Micrografia da região de mistura com presença de bainita.

Fonte: Autoria própria.

O Gráfico 2 apresenta os valores de microdureza Vickers ao longo da junta soldada por fricção. Entre a variação da microdureza apresentada nas diferentes regiões da solda, observou-se um aumento na dureza em aproximadamente $40 \%$ na zona de mistura (ZM) comparado ao metal base. De acordo com [13], a razão deste aumento de dureza pode ser explicada devido à formação de agregados de carbetos pelos 
elementos de liga e a redução no tamanho de grão, normal sob as circunstâncias de alta temperatura e alta pressão. No caso das regiões de metal de base e da zona termomecanicamente afetada, os valores de dureza apresentaram uma tendência semelhante como esperado em regiões de microestrutura composta de ferrita e perlita. No trabalho de [13], as amostras soldadas por fricção nas ligas SAE4140 e 1050 apresentaram comportamento semelhante no perfil de dureza.

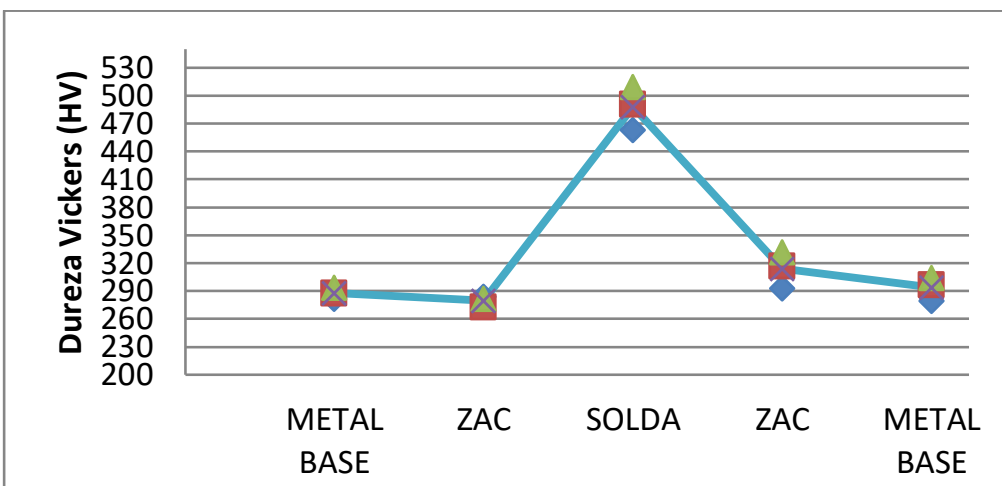

Gráfico 2: Perfil de mircodureza Vickers ao longo da junta soldada por fricção.

Fonte: Autoria própria.

O aporte térmico, como foi dito anteriormente, tem relação direta com as propriedades mecânicas. Porém no processo de solda por fricção o aporte térmico tende a ser menor que em processos de soldagem por arco elétrico, consequentemente tende a afetar menos as propriedades do metal de base. A Figura 7 mostra o gráfico do teste de tração obtido em uma amostra da junta soldada por fricção.

Durante o ensaio de tração, amostras soldadas por fricção, apresentaram um comportamento dúctil, sem um ponto de escoamento bem definido e o valor do limite de resistência médio de $841 \mathrm{MPa}$. A diminuição no limite de resistência, comparado com o LR de 889Mpa obtidos no estado de entrega, pode ser justificado pela modificação na orientação cristalográfica apresentada pela menor deformação e recristalização na curta ZTMA. Os corpos de prova romperam na região do metal base próxima à ZTA conforme mostrado na Figura 8. Este comportamento se mostrou coerente com o perfil de microdureza, tornando mais provável a ruptura no metal base, uma vez que podemos correlacionar a dureza com o limite de resistência.

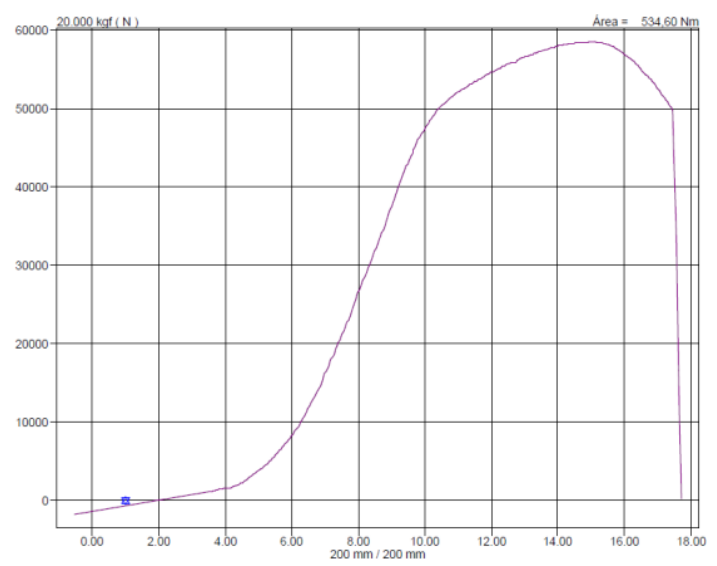

Figura 7. Curva do teste de tração do tubo SAE4130 soldado por fricção.

Fonte: Autoria própria. 


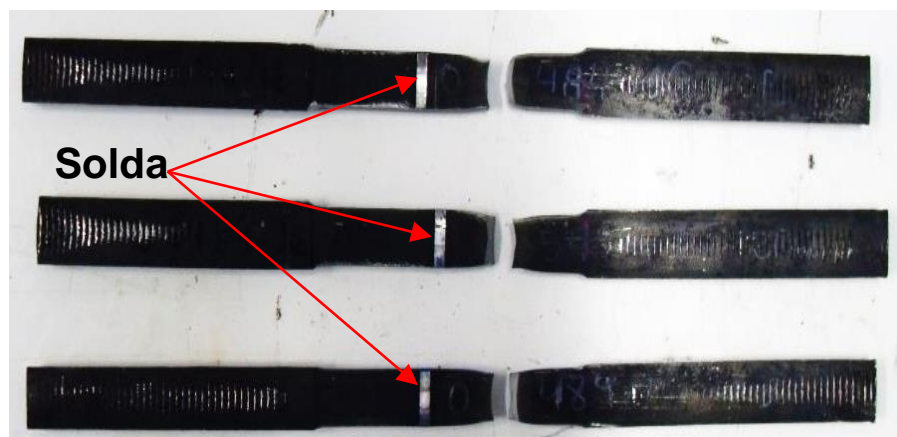

Figura 8: Corpos de prova soldados por fricção após ensaio de tração. Ruptura no metal base. Fonte: Autoria própria.

\section{CONCLUSÃO}

A junta soldada por fricção apresentou uma tendência a manter o limite de resistência próximo ao do material no estado de entrega, porém, a microestrutura apresentada pode resultar em falha prematura por fragilidade devido aos altos valores de microdureza observados na região de mistura.

Com base em tudo o que foi discutido e estudado considera-se que foi possível avaliar a possibilidade de aplicar o processo de solda por fricção em substituição aos processos de soldagem por arco elétrico com gás de proteção e ao processo de usinagem e adesivo para alto troque.

O processo de solda por fricção mostrou ser indicado para a recuperação de hastes de sondagens, uma vez que apresentou uma menor variação do limite de resistência. Além disso, é um processo que combina efetividade e baixo tempo de produção ao se comparar com as etapas de preparo para uma solda GMAW, por exemplo.

Contudo, estudos de campo são necessários para comprovar a eficácia do processo de fricção como método de recuperação.

\section{Agradecimentos}

Os autores agradecem à Geosol, à Fundação Victor Dequech e a REDEMAT/UFOP.

\section{REFERÊNCIAS}

1 CARVALHO, R.F., Análise da Eficiência da Sondagem Rotopercussiva na Jazida de Ferro de Serra Sul, Serra dos Carajás-Pará. Ouro Preto, MG: Escola de Minas, Universidade Federal de Ouro Preto, 2013. (Dissertação de Mestrado Profissional em Engenharia Geotécnica).

2 COSTA FILHO, O. G., Análise de sensibilidade do desempenho da sondagem aos parâmetros operacionais. Ouro Preto, MG: Escola de Minas, Universidade Federal de Ouro Preto, 2015. (Dissertação de Mestrado Profissional em Engenharia Geotécnica).

3 FORTES, CLEBER. Apostila Metalurgia da Soldagem. ESAB, Contagem, 2005.Disponível

em: http://www.esab.com.br/br/pt/education/apostilas/upload/apostilametalurgiasoldagem.p df. Acesso em 15 out. 2016.

4 MODENESI, P. J; MARQUES, P. V; SANTOS, D. B. Introdução à Metalurgia da Soldagem. Universidade Federal de Minas Gerais, Belo Horizonte, 2012. 208p. Disponível em: http://demet.eng.ufmg.br/wp-content/uploads/2012/10/metalurgia.pdf. Acesso em 15 out. 2016. 
5 SILVA, F. L. T. da; JÚNIOR, L. G. Soldagem por Fricção. Infosolda, 2015. Disponível em:<http://www.infosolda.com.br/images/Downloads/Artigos/processos_solda/soldage m-por-friccao.pdf>. Acesso em 15 out. 2016.

6 HAUPT, William. Ensaios Mecânicos e Análise Microestrutural de Tubos Soldados por Fricção. Dissertação (Mestrado em Engenharia) - Programa de Pós-Graduação em Engenharia de Minas, Metalúrgica e de Materias, Escola de Engenharia da Unaiversidade Federal do Rio Grande do Sul - Porto Alegre, 81p, 2013.

7 FAES, K., VERMEIRSCH, W., DENYS, R., VAN DER DONCKT, E. Influence of forge pressure on properties of friction welded pipelines using intermediate rings. Science and Technology of Welding and Joining, p455-451, Abril 2008.

8 MARQUES, P. V., MODENESI, P. J., Algumas Equações Úteis em Soldagem, São Paulo: Soldag. Insp., Vol. 19, №. 01, p.091-102, Jan/Mar 2014.

9 MARQUES, P. V., MODENESI, P. J., Algumas Equações Úteis em Soldagem, São Paulo: Soldag. Insp., Vol. 19, №. 01, p.091-102, Jan/Mar 2014

10 HULKA, K.; HEISTERKAMP, F. Weldability Considerations in the Development of Structural Steels. Third International Conference on HSLA Steels. Proceedings the Chinese Society for Metals, Beijing, p.543-551, 1995.

11 DE FARIA, P.E., BRACARENSE, A.Q., Soldagem por fricção. Infosolda 2003. Disponível em: <www.infosolda.com.br/new_site/getFilephp?t=d\&i=139>. Acesso em: 15 out. 2015.

12 ASM HANDBOOK. Metallography and Microstructures. ASM International. V.9, 2004, $1139 \mathrm{p}$.

13 CELIK, SARE; ERSOZLU, ISMAIL. Investigation of the mechanical properties and microstructure of friction welded joints between AISI 4140 and AISI 1050 steels. Balikesir: Materials \& Design, v 30, p. 970-976, 2009.. 